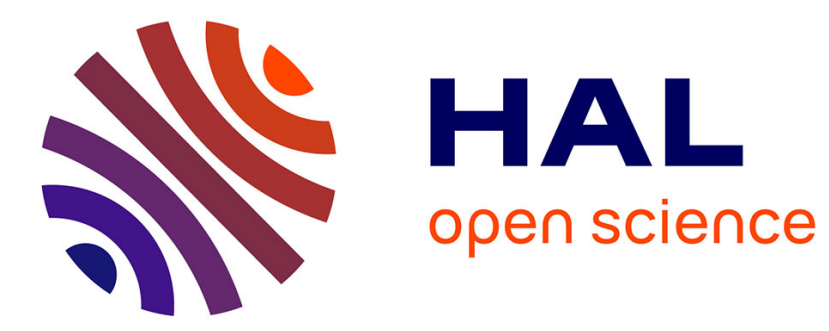

\title{
In situ and real time investigation of directional solidification of Al-Ni alloys by synchrotron imaging
}

Guillaume Reinhart, H. Nguyen-Thi, J. Gastaldi, B. Billia, Nathalie

Mangelinck-Noël, T. Schenk, J. Hartwig, J. Baruchel

\section{To cite this version:}

Guillaume Reinhart, H. Nguyen-Thi, J. Gastaldi, B. Billia, Nathalie Mangelinck-Noël, et al.. In situ and real time investigation of directional solidification of Al-Ni alloys by synchrotron imaging. Materials Science Forum, 2006, 508, pp.75-80. 10.4028/www.scientific.net/MSF.508.75 . hal-00068030

\section{HAL Id: hal-00068030 \\ https://hal.science/hal-00068030}

Submitted on 21 Apr 2020

HAL is a multi-disciplinary open access archive for the deposit and dissemination of scientific research documents, whether they are published or not. The documents may come from teaching and research institutions in France or abroad, or from public or private research centers.
L'archive ouverte pluridisciplinaire HAL, est destinée au dépôt et à la diffusion de documents scientifiques de niveau recherche, publiés ou non, émanant des établissements d'enseignement et de recherche français ou étrangers, des laboratoires publics ou privés.

\section{(c)(1)}

Distributed under a Creative Commons Attribution| 4.0 International License 


\title{
In situ and real time investigation of directional solidification of $\mathrm{Al}$ - Ni alloys by synchrotron imaging
}

\author{
G. Reinhart ${ }^{1, a}$, H. Nguyen-Thi ${ }^{1, b}$, J. Gastaldi ${ }^{2, c}$, B. Billia ${ }^{1, d}$, N. Mangelinck- \\ Noël $^{1, e}$, T. Schenk ${ }^{3, f}$, J. Härtwig ${ }^{3, g}$, J. Baruchel $^{3, h}$ \\ ${ }^{1}$ L2MP, UMR CNRS 6137, Université Paul Cézanne (Aix-Marseille III), Case 142, 13397 Marseille \\ Cedex 20, France
}

${ }^{2}$ CRMCN, Campus Luminy, Case 913, 13288 Marseille Cedex 9, France

${ }^{3}$ E.S.R.F, BP 220, 38043 Grenoble, France

aguillaume.reinhart@L2MP.fr, ${ }^{b}$ henri.nguyen-thi@L2MP.fr, ${ }^{\circ}$ gastaldi@crmcn.univ-mrs.fr,
bernard.billia@L2MP.fr, ${ }^{e}$ nathalie.mangelinck@L2MP.fr, ${ }^{\text {f }}$ 'schenk@esrf.fr, ${ }^{9}$ haertwig@esrf.fr,

Keywords: Directional Solidification, Dendrites, Morphological Stability, X-ray Radiography, X-ray Topography, strains

\begin{abstract}
Solidification is a dynamic phenomena and, as a consequence, it is of major interest to be able to investigate this process by in situ and real time observation. With synchrotron sources, this can be achieved by applying X-ray Imaging techniques (Radiography and Topography). Hence it is possible to follow the dynamical selection of solidification pattern on metallic alloys and to observe strain effects during growth process. In this paper, we present results obtained by using separately the two imaging techniques for the study of the microstructure formation during $\mathrm{Al}-\mathrm{Ni}$ alloys solidification.
\end{abstract}

\section{Introduction}

During directional solidification of a binary alloy, the solid-liquid interface exhibits a variety of patterns (cells, dendrites) that are due to the Mullins-Sekerka instability and governed by the growth conditions. It is well known that properties of the grown material are largely controlled by the microstructures left in the solid during processing. Thus, a precise mastering of the solidification is essential to tailor products in a reproducible fashion to a specified quality. One major difficulty for this study is the real time and in situ observation of the interface, especially for metallic alloys. A possibility is to use an intense and coherent synchrotron X-ray beam. By different X-ray imaging techniques (absorption/phase contrast radiography and diffraction topography), the directional solidification of aluminium-nickel alloys was studied. The results show the great potential of these techniques for the study of dynamical selection of the solidification pattern, and the coupling between stress effects and microstructure formation in solidification processing.

In this paper, we present results obtained by the two imaging techniques on the solidification patterns of Al - Ni alloys. Dynamical interaction between columnar interface microstructure and self-stress, resulting in unforeseen mechanical deformation phenomena, is brought to light by means of in situ and real-time synchrotron X-ray topography at LURE, while X-ray radiography at ESRF enabled us to follow the pattern formation during the very early stages of initial transient following the planar interface breakdown.

\section{$\mathrm{X}$-ray imaging techniques}

Absorption and phase contrast radiography: It was recently demonstrated that absorption and phase contrast radiography with synchrotron radiation is efficient to image dendritic growth [1 - 3]. Conventional absorption radiography is a non-destructive technique based on local changes in the amplitude of the X-ray beam transmitted through the sample. A monochromatic X-ray beam 
illuminates the sample and a 2D-detector is placed close to the sample (Fig.1a). In alloy systems, the contrast mainly results from segregation, which is proportional to the atomic number of the components and their concentration [4]. Phase contrast radiography is a new X-ray imaging technique, which takes advantage of the large transverse coherence of the synchrotron beam [5,6]. In this imaging technique, contrasts are produced by interference between parts of the wave front of the transmitted beam that have locally undergone different phase shifts, generated by differences in the electron density of the non-homogeneous sample. The experimental device is similar to the absorption radiography one. The only difference is the distance $D$ between the sample and the detector, which must be adjusted owing to the characteristic spatial frequencies of the inhomogeneities of the analysed sample. In the case of the present samples the observed contrast is due to a superposition of both mechanisms, absorption and phase radiography.

X-ray diffraction topography: X-ray diffraction topography (XRT) is a non-destructive imaging technique primarily used for the characterization of defects and long-range distortions in crystals [7]. For studying directional solidification of binary alloys, Synchrotron XRT is performed in the white-beam mode (Fig.1b), which is very useful in our case because it does not require a previous knowledge of the crystal orientation and because several diffraction images are provided in one shot. Despite its relatively poor spatial resolution (few micrometers), this technique allows to analyse, at once, a large volume (few $\left.\mathrm{cm}^{2} \times 0.1 \mathrm{~cm}\right)$ with a large sensitivity range $\left(<10^{-8} \ldots 10^{-3}\right)$. The high intensity of synchrotron radiation makes it possible to record images in reasonable time (about one second) so that direct observation is enabled, which is crucial for studying dynamical phenomena in real time. The detector we used at LURE was either nuclear plates or high resolution films.
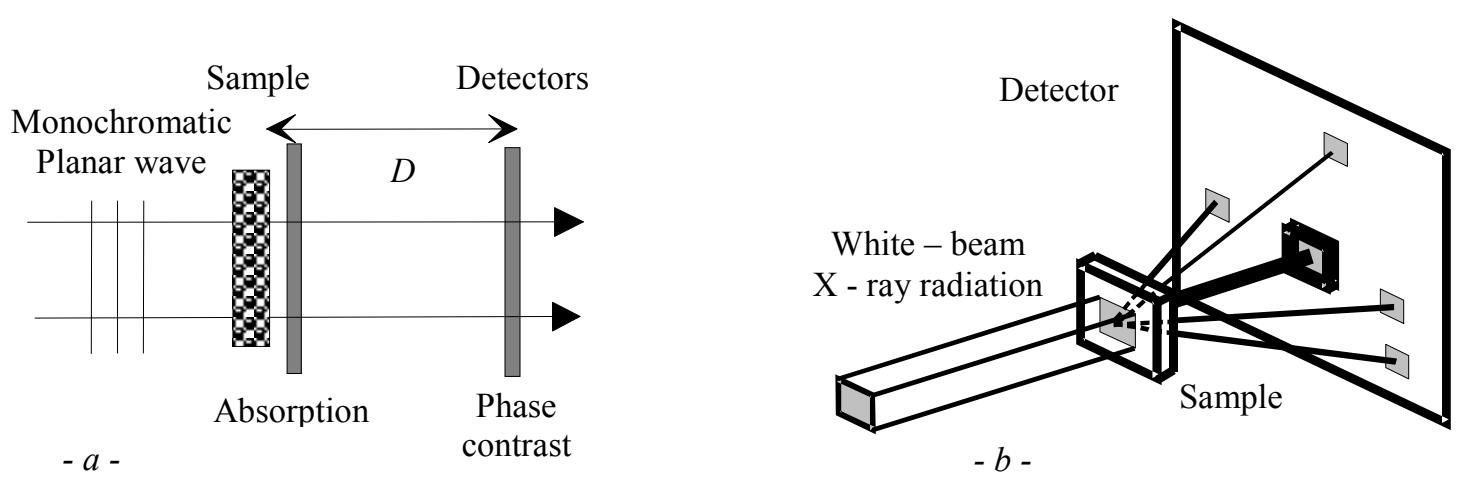

Fig. 1. Sketch of X-ray Radiography and Topography

\section{Experimental apparatus and samples}

The experiments reported here were conducted respectively at LURE (Orsay, France) for XRT and at ESRF (European Synchrotron Radiation Facility, Grenoble, France) for X-ray radiography. In both cases, the experimental apparatus were very similar and were described in detail elsewhere [2]. Thin samples of $\mathrm{Al}-5.7 \mathrm{wt} \% \mathrm{Ni}$ and $\mathrm{Al}-3.5 \mathrm{wt} \% \mathrm{Ni}$ were adjusted into graphite crucibles, which were mounted in a holder connected to a motorised translation. Particular care was taken for the design of the graphite crucibles and the furnace to reduce thermal stresses in the close vicinity of the solidification interface. The thickness of sample was reduced to its minimum value, about $0.16 \mathrm{~mm}$, to lower convection effects and also to have only one single layer of cells or dendrites. Solidification experiments were carried out horizontally at LURE and vertically at ESRF, in a temperature gradient of the order $20 \mathrm{~K} / \mathrm{cm}$ and within a velocity range of $1-50 \mu \mathrm{m} / \mathrm{s}$. During translation, the main surface of the sample $\left(37 \times 6 \mathrm{~mm}^{2}\right)$ was set perpendicular to the incident X-ray beam, which was either a monochromatic X-ray beam $(13.5 \mathrm{keV})$ for absorption/phase contrast radiography or a white-beam radiation to perform X-ray diffraction topography. 


\section{Cumulative mechanical moments and microstructure deformation induced by growth shape in columnar solidification}

Synchrotron white-beam X-ray topography at LURE (Orsay, France) has enabled us to carry out in situ and real-time observation of the formation of columnar microstructure in dilute aluminum alloys. We investigated the strains caused by solute segregation, first in the solid adjacent to the solid-liquid interface and then in microstructure formation [8,9]. During the microstructure formation, we observed an unforeseen deformation of the columnar pattern in reaction to self-stress imposed by cumulative mechanical moments built in the growth process [10]. A sudden cell rotation, revealed by a jump of the columnar body image (Fig.2a and 2b), is brought into light. This phenomenon is unpredictable and complete in about 1 second, as it could be seen on the control monitor. In fact, it should be emphasised that cells are attached by a thin solid neck to the native solid grain as visible in Fig2a. With the microstructure development, each columnar body is concomitantly generating two cumulative mechanical moments acting on it: As growth direction is horizontal, one moment is the extrinsic cumulative bending moment due to Earth gravity, the second is the intrinsic cumulative torque induced by shear stress [10]. The latter moment is caused by the variation of tangential strain along the columnar contour resulting from the variation of local solute concentration. The precise description and evaluation of this moment necessitate the detailed knowledge of the stress and composition fields and of the column shape, which is definitely out of reach in present experiments Nevertheless, it is of value to notice that bending moment is a quadratic function of time, whereas torque moment is only a linear function of time. Consequently, bending mechanism is predicted to always dominate torsion phenomena after some time for horizontal solidification. In addition, in microgravity environment, only the intrinsic torque moment would act of gravity. It follows that, due to the simultaneous action of two moments, the yield stress is exceeded which causes the sudden rotation of the cell neck. The process is all the more easy as each column is entirely surrounded by melt, and metals are tremendously ductile at melting point.

By repetition at several places in the array as directional solidification progresses, cell disorientation progressively results in massive loss of column images, which eventually gives a "gap-toothed" topograph (Fig.2c) with a spreading of columns. It is worth noticing that these cells physically are still part of the microstructure front. Grain polygonisation will subsequently occur due to the nucleation in the cell boundaries of arrays of dislocations extending along the growth direction where adjacent columnar bodies with slightly different orientation join.
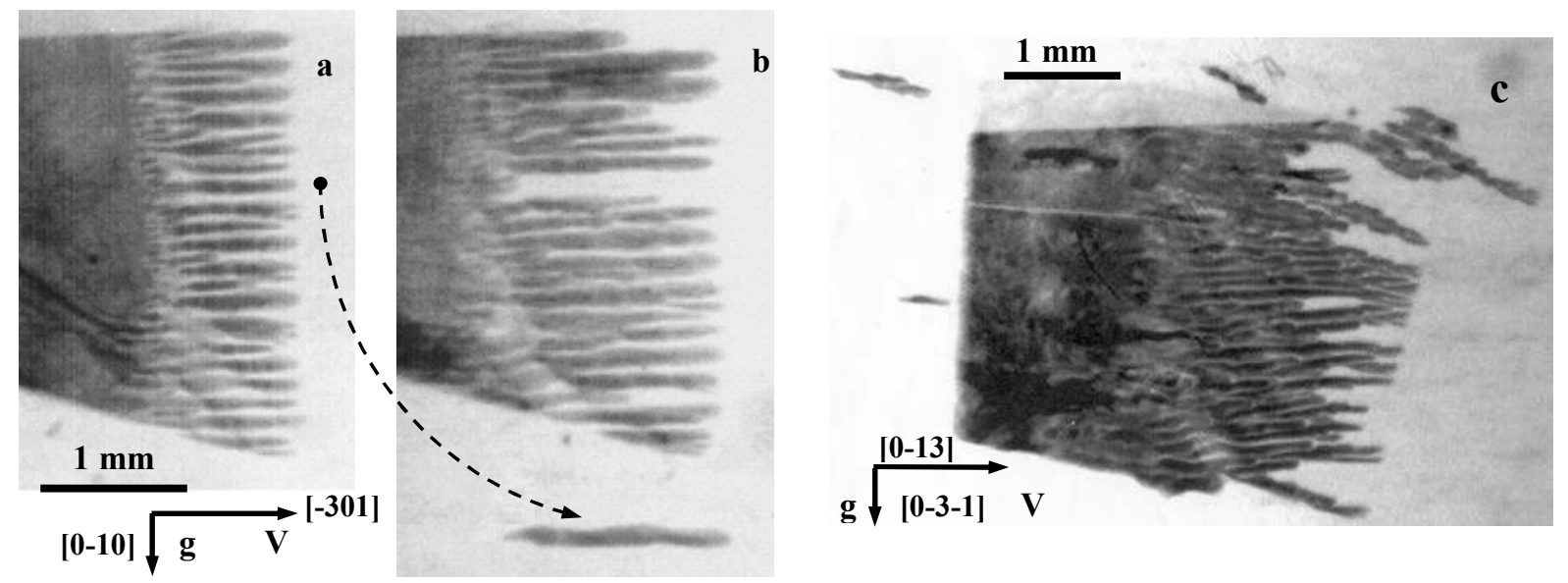

Fig. 2. Directional solidification of an $\mathrm{Al}-5.7 \mathrm{wt} \% \mathrm{Ni}$ sample. $\mathrm{V}=2.2 \mu \mathrm{m} / \mathrm{s}$. (200)-reflection. -a) $900 \mathrm{~s},-\mathrm{b}) 1260 \mathrm{~s}$. and -c) Repeated disorientation of columns breaking the microstructure image into a gap-toothed array lying among many pieces. $\mathrm{Al}-5.7 \mathrm{wt} \% \mathrm{Ni}$. V $=2.5 \mu \mathrm{m} / \mathrm{s}$. (131)-reflection. 


\section{Initial transient during directional solidification of $\mathrm{Al}-3.5 \mathrm{wt} \% \mathrm{Ni}$ alloy}

We consider the upwards solidification of $\mathrm{Al}-3.5 \mathrm{wt} \% \mathrm{Ni}$ alloys. The main purpose was to explore the dendritic columnar growth, in particular the initial transient. Three series of experiments were carried out with the same thermal gradient $(20 \mathrm{~K} / \mathrm{cm})$ and for different pulling rates within the range of $1-50 \mu \mathrm{m} / \mathrm{s}$. Fig. 3 shows a sequence of three successive images taken during the initial solidification transient for a growth rate of $1.0 \mu \mathrm{m} / \mathrm{s}$ that illustrate the power of X-ray radiography for the investigation of directional solidification of metallic alloys.
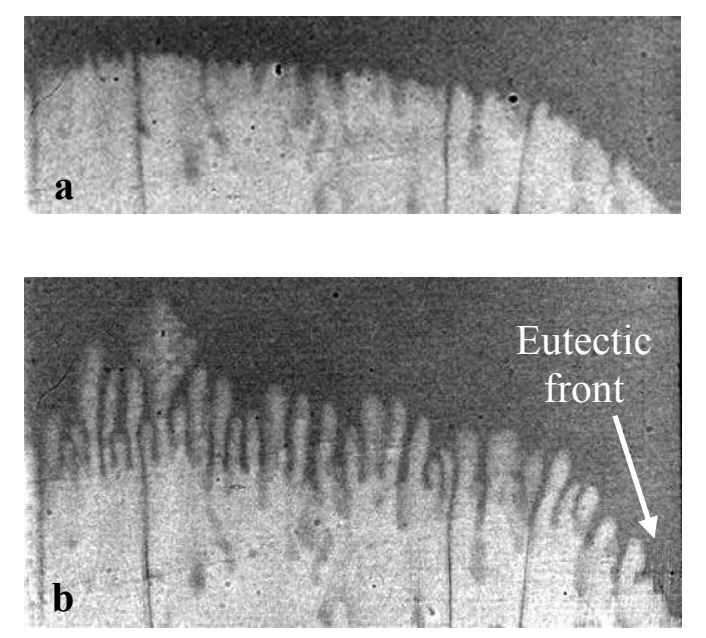

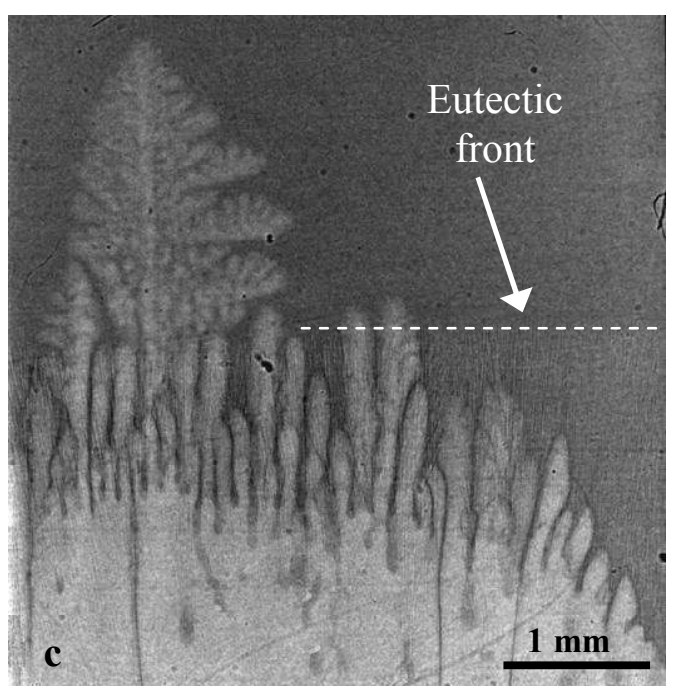

Fig. 3. Sequence of 3 images of Al-3.5wt $\%$ Ni solidification, recorded during the initial transient by X-ray radiography, $\mathrm{G}=20 \mathrm{~K} / \mathrm{cm}, \mathrm{V}=1 \mu \mathrm{m} / \mathrm{s}$ : a) $\left.\left.\mathrm{t}=\mathrm{t}_{0}+240 \mathrm{sec}, \mathrm{b}\right) \mathrm{t}=\mathrm{t}_{0}+1344 \mathrm{sec}, \mathrm{c}\right) \mathrm{t}=\mathrm{t}_{0}+$ $3206 \mathrm{sec}$, The solid, close to pure aluminum, appears in grey while the Ni enriched liquid is dark.

These images show the time evolution of the interface pattern, from the breakdown of the planar interface to the subsequent development of the microstructure. In Fig.3a $\left(t=t_{0}+240 \mathrm{sec}\right.$ with $t_{0}$ the time when the first disturbances are visible on the recorded image), the initial planar front is undergoing the Mullins-Sekerka instability and disturbances are clearly apparent along the whole interface. At this stage, it is possible to determine an average wavelength $\lambda_{i}$ for the microstructure, $\lambda_{i}=140 \mu \mathrm{m}$. Further development of the pattern occurs with a progressive increase of the amplitude of the disturbances (Fig.3b, $t=t_{0}+1344 \mathrm{sec}$ ). In Fig.3b, one can see on the left that sidebranches begin to growth on a few primary trunks, which indicates the inception of the formation of dendrites, while on the right the eutectic front begins to form, due to the local increase of solute concentration in the liquid. In the subsequent stage, both the dendrite amplitude and lateral size increase concomitantly, with screening causing a strong decrease of the growth of the neighbouring cells or dendrites, which are progressively captured by the eutectic front (Fig.3c, $t=t_{0}$ $+3206 \mathrm{sec}$ ). The steady-state growth would be reached when the dendrite propagates at a velocity equal to the applied pulling rate. In our experiments, this steady state was not achieved due to both the very low value of the partition coefficient $\left(k \approx 10^{-3}\right)$ and the limited sample length. Nevertheless, before reaching the end of the sample, the general shape of the microstructure did not change drastically and was composed of a single dendrite protruding markedly into the liquid phase (steepling phenomenon) with an eutectic front at its base like in Fig.3c (clustering phenomenon). It is well know that the origin of these two effects is convection, induced by radial thermal and solutal gradients [11]. Consequently, although the thickness of the sample was small (about $200 \mu \mathrm{m}$ ), convection was still present in our experiments. Nevertheless, to our knowledge, this is the first dynamical observation of the establishment of these phenomena during solidification processing. 
Conversely to experiments at LURE, ESRF solidifications were performed vertically upwards and we only used the X-ray radiography. Thus, mechanical effects were not easy to reveal like experiments with X-ray topography. Nevertheless, the bending mechanism was also revealed out by the rotation of secondary arms when they are long enough. This is shown in Fig. 4 for one secondary arm, with an orientation indicated by the dashed line (1), which suddenly switched to a new orientation (2) with a rotation angle of $5.5^{\circ}$. By this way, the secondary arm reached a final position parallel to the arms below. This phenomenon was observed between two successive images, taken with a time interval of 21 seconds, which confirms that this effect is complete in a very short time. Obviously, this bending mechanism was not visible on the primary arm, which are parallel to the growth direction, but on the secondary arms.
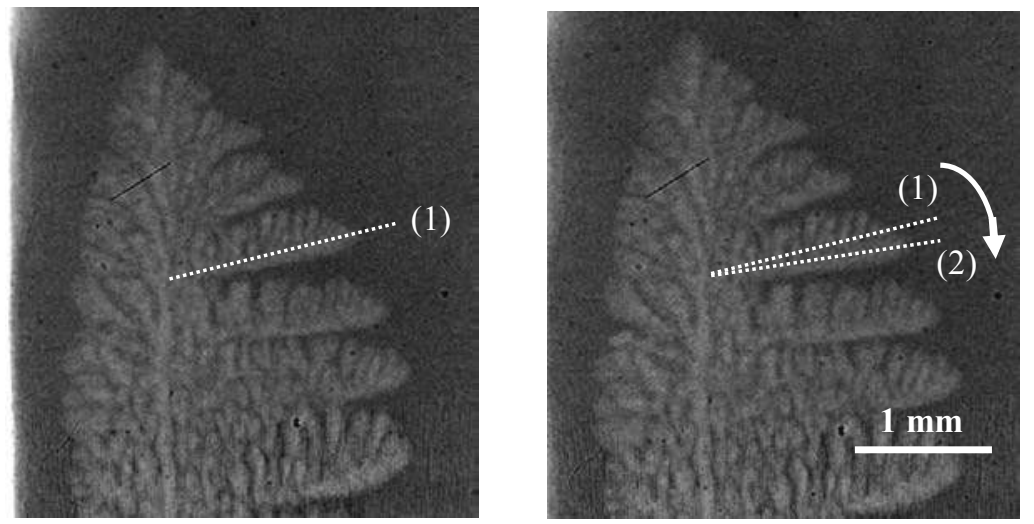

Fig. 4. Two successive images recorded by in situ and real-time X-ray radiography of $\mathrm{Al}-3.5$ $\mathrm{wt} \% \mathrm{Ni}$ alloy solidification at $\mathrm{V}=1.0 \mu \mathrm{m} / \mathrm{s}$, showing the rotation of a secondary arm from orientation (1) to (2) (elapsed time between the two images is 21 seconds)

\section{Conclusion}

This paper reports the separate application of two X-ray complementary imaging techniques: absorption/phase contrast radiography and topography. X-ray radiography gives a direct picture of the solid-liquid interface, while X-ray diffraction topography gives the strain field within the microstructure. The results demonstrate the great potential offered by the future combination of these techniques when all the technical difficulties will be solved.

By X-ray topography, the effect of global self-stress cumulating moments was demonstrated, causing critical mechanical effects in columnar solidification. Those global self-stress constraints demand new efforts to incorporate them in theoretical modelling and numerical simulation [12]. Also further studies of the disorientation phenomena are mandatory, more especially to get the quantitative information needed to sustain sound modelling. On the other hand, X-ray radiography enabled us to follow the pattern formation dynamics so that we are currently implementing at ESRF (European Synchrotron Radiation Facility) experiments combining the two imaging techniques: Xray topography (strains, defects) and radiography (shape, solute segregation). Pursuing the investigation of the interactive dynamics of solidification microstructure and global self-stress effects will ultimately provide a significant contribution of wide interest because global mechanical constraints are of general relevance for pattern formation at solid surfaces/interfaces in systems far from equilibrium. 


\section{References}

[1] R. H. Mathiesen, L. Arnberg, K. Ramsokar, T. Weitkamp, C. Rau, A. Snigirev, Metallurgical and Materials Transaction B 33B (2002) 613-623.

[2] H. Nguyen Thi, H. Jamgotchian, J. Gastaldi, J. Härtwig, T. Schenk, H. Klein, B. Billia, J. Baruchel, Y. Dabo, J. Phys. D: Appl. Phys. 36 (2003) A83-A86.

[3] H. Yasuda, I. Ohnaka, K. Kawasaki, A. Sugiyama, T. Ohmichi, J. Iwane, K. Umetani, Journal of Crystal Growth 262 (2004) 645-652.

[4] W. F. Kaukler, F. Rosenberger, Metall. And Mater. Trans. A 25A (1994) 1775.

[5] A. Snigirev, I. Snigireva, V. Kohn, S. Kuznetsov, I. Schelokov, Rev. Sci. Instrum. 66 (1995) 5486.

[6] P. Cloetens, R. Barrett, J. Baruchel, J. P. Guigay, S. M., J. Phys. D: Appl. Phys. 29 (1996) 133.

[7] D. K. Bowen, B. K. Tanner: High-resolution X-ray diffractometry and topography, Taylor \& Francis Ltd, 1998

[8] G. Grange, J. Gastaldi, C. Jourdan, B. Billia, J. Physique III 4 (1994) 293.

[9] G. Grange, C. Jourdan, J. Gastaldi, B. Billia, Acta Material 45 (1997) 2329.

[10]B. Billia, G. Gastaldi, G. Grange, N. Bergeon, H. Nguyen Thi, H. Jamgotchian, Phys. Rev Lett. (2004), To appear

[11]M. H. Burden, D. J. Hebditch, J. D. Hunt, J. Cryst. Growth 20 (1973) 121-124.

[12]B. J. Spencer, P. W. Voorhees, S. H. Davis, G. B. McFadden, Acta Metall. Mater. 40 (1992) 1599. 